\title{
Study on the Countermeasures of the Gravity Model of Wuhan City Circle
}

\author{
$\mathrm{Gu} \mathrm{Yi}{ }^{1}$ and Guo Pian ${ }^{2}$ \\ ${ }^{1}$ Golf school of Jianghan university, Wuhan \\ ${ }^{2}$ business school of Jianghan university, Wuhan \\ 1039857158@qq.com²2053501979@qq.com
}

Keywords: Wuhan city circle; Gravity model; Gravity pattern

\begin{abstract}
This article from the industrial structure, technological innovation ability, the development of financial markets, the problems existing in the current human resource allocation policy, further expounds the bottleneck for the further development of Wuhan in the city circle, and by introducing the gravity model research, put forward a series of countermeasures in view of the Wuhan city circle development. Such as optimization of Wuhan city circle of the industrial structure, accelerate the financial integration of Wuhan city circle and the financial center construction, to strengthen the construction of legal system, optimize the environment of market integration, and strive to enhance the level of opening to the outside world. To sum up, the improvement model of Wuhan city circle reflects the urban pattern of " $1+8$ ". Only by making clear their respective advantages and disadvantages can the gravitational effect of Wuhan urban circle be fully exerted.
\end{abstract}

\section{Introduction}

Wuhan city circle is an important node in China's "central rise" strategy and the most dynamic region in Hubei. USES the combination of theory and empirical research, this paper analyzes the four aspects of the Wuhan city circle of retained difficulty, promote the Wuhan city circle of gravity method is proposed, in order to enhance the competitiveness of the city circle, environment friendly forces and the comprehensive influence

\section{Obstruct Wuhan City Circle to Play the Gravitational Force of the Bottleneck}

\section{The Industrial Structure needs to be optimized}

In the process of economic transformation, traditional industries are faced with many shortcomings: on the one hand, due to poor technological innovation ability, enterprises have weak competitiveness. Thirdly, the ability of sustainable development is weak. Traditional industries are faced with many problems such as pollution, energy consumption and technological content. On the other hand, with the increasing cost of production factors, the serious problems of environment and resources have limited the development of traditional industries. Finally, unreasonable industrial layout. At the same time, due to the lack of reasonable and effective planning, the competition in the local and the industry has been intensified. Due to the internal competition of the conformation, the phenomenon of excess capacity becomes obvious, and the social resources are not used reasonably and effectively, which greatly weakens the overall efficiency of the local production system.

\section{Lack of scientific and technological innovation capability}

First, the mismatch between the virtual economy and the real economy. Second, the current industrial structure and some energy and price mechanisms do not match the green development needs of the world.

The development of financial market lags behind industrial development

Disconnect between industrial development and market construction

First, the industry is developed and the market is backward. Some industries of Wuhan city circle are relatively developed, such as automobile, textile, metallurgy, electronic information and other 
industries. These industries are not only the key pillar of Wuhan city circle, but also the main commodity flow in the region. But for these industries, there is still no large professional market matching the scale and radiation force. Due to the backwardness of the market, the marketing efficiency of the local manufacturing industry is limited and the competition effect is reduced.

Second, the market is developed and the industry is backward. In the consumer goods market, Wuhan area has obvious competitive advantage. But in the consumer goods industry, Wuhan is in a relatively weak position. In the developed consumer goods market, it is still dominated by foreign products, especially high-end consumer goods.

\section{Unbalanced development of the market system}

One is the unbalanced regional layout. According to statistics, Wuhan is in the consumer goods market, the total amount of consumer retail goods occupies the whole Wuhan city circle $60 \%$. The market in the circle is basically concentrated in Wuhan, and the development of surrounding cities is obviously backward.

Second, the market structure is unbalanced. There are many consumer goods market in Wuhan city circle, but the production factor market is badly developed. The comprehensive market is many, but the specialized characteristic market is few, especially the large professional wholesale market with the regional radiation force is insufficient. This leads to the imbalance of the whole market structure in Wuhan city circle.

\section{The intercity market interaction is not enough}

In terms of industrial services, the entire city circle lacks a direct professional market. On the other hand, there is a lot of repetition in market construction. Due to the lack of unified planning, it is obvious to repeat the construction phenomenon in the areas of flower arrangement, border area, agricultural and sideline products and construction market. ,

\section{Existing problems in human resource allocation policy}

The current human resources policy in Wuhan city circle still has room for improvement in configuration. On the one hand, there is a great demand for talents in small and medium-sized cities and rural areas. On the other hand, the utilization of surplus rural labor force is insufficient. In order to solve these two problems, we need to establish a set of resource allocation policy to guide the flow of talents, so that the labor force can flow freely.

\section{Build the Gravity Model of Wuhan City Circle Leading Role}

\section{Principle of gravity model}

The gravity model currently used is based on Newton's gravitation model, and its general form is (liu ji-born et al., 2000) : Fab=K QaQb ab (1)

In the formula: Fab refers to the gravity of city a to city $\mathrm{b} ; \mathrm{K}$ is the gravitational constant; Qa and $\mathrm{Qb}$ are the quality of $\mathrm{a}$ and $\mathrm{b}$ respectively; $\mathrm{Ab}$ is the distance between the two cities; It is the distance friction coefficient.

\section{Urban gravity model based on urban competitiveness and environmental friendliness}

Demand and complementarity between city determines the strength of the contact between the two cities, we can put the complementarity between the city and needs to understand: if a city some condition is superior to b city, on the other hand, b city has superior other conditions than a city, make ab cities exist complementary advantages and disadvantages. There is a strong complementarity between these two cities. In the case that city a is superior to city $b$, certain conditions of a can satisfy certain deficiencies of city $b$, which leads to a greater demand for city a in city b. Such complementarity and demand can be determined by evaluating the relative merits of each city relative to other cities (urban competitiveness and environmental friendliness).

Based on the complementarity between the city and the demand, measured by the urban competitiveness of the city comprehensive ability, using gravity model, thus suggesting a city quantitatively the degree of complementarity and demand, used to measure the economic links between the city. The model of urban gravity based on urban competitiveness and environmental friendliness is as follows:

$\mathrm{Fab}=\mathrm{K}$ sigma $\mathrm{h}=0$ nwa-mna-mna-mna-mna-mna-m $\mathrm{x}, \mathrm{t}=0 \mathrm{nWb}-\mathrm{nnb}-\mathrm{m} * \mathrm{pb}-\mathrm{nqb}-\mathrm{m}$ sigma $\mathrm{t}=0$ 
n(ba-tcab-ttab-t)(2)

Where: Fab is the attraction between city $\mathrm{a}$ and $\mathrm{b} ; \mathrm{K}$ is the gravitational constant; Wa-m and pa- $m$ are the weight and quantization values of the $m$ factors that determine the competitiveness of cities in city a. Na-m and Qa-m are the weight and quantization values of the $\mathrm{m}$ factors determining the urban environmental friendliness in city a. $\mathrm{Wb}-\mathrm{n}$ and $\mathrm{pb}-\mathrm{n}$ are the weight and quantization values of the NTH factor determining the competitiveness of cities in city $b$ respectively; Nb-n and qb-n are the weight and quantization values of the NTH factor determining the urban environmental friendliness in city $b$ respectively. The weight, transportation cost and time of the $t$ - type transportation mode of city a to city $b$ respectively.

\section{Improvement of model}

On the basis of the original city of gravity model, the introduction of relative gravity vector constants improved gravity model, vector is the direction for, competitive big city to competitive small city, the relative gravity constants as follows:

$\mathrm{K}=\mathrm{G}(\mathrm{e}+\mathrm{Sab})$ (a indicates b) (3)

Where: $\mathrm{K}$ is the relative gravity constant; $\mathrm{G}$ is the dimensional transformation coefficient, whose value is 1 , whose function is to remove the unit of gravitation constant; for the modulus operator; $\mathrm{E}$ is the unit vector; Sab is a relative gravitational constant adjustment coefficient, which can change the relative gravitational constant size. The expression of $\mathrm{Sab}$ is:

$\mathrm{Sab}=$ voa - ob Dab (4)

$$
\mathrm{V}=(\mathrm{Qa} 2+\mathrm{Qb} 2)+\mathrm{Qb}(\mathrm{Qa}) 2(5)
$$

Where: $\mathrm{v}$ is the regulation coefficient, which is used to change the size of $\mathrm{Sab}$; $\mathrm{Ob}$ and oa respectively represent the vectors of any point o to city $b$ and a in space; Dab is the space distance between city a and $\mathrm{b}$; $\mathrm{Qa}$ and $\mathrm{Qb}$ are the competitiveness of city a and $\mathrm{b}$ respectively.

When calculating the gravity of city a to city $\mathrm{b}$, the relative gravity constant $\mathrm{K}$ can be deduced according to the rules of vector operation and equation (4).

$\mathrm{Oa}-\mathrm{ob}=\mathrm{ab}(6)$

$\mathrm{Ab}=\mathrm{Dab} * \mathrm{e}(7)$

There are: $\mathrm{Sab}=\mathrm{v} * \mathrm{e}(8)$

$\mathrm{K}=\mathrm{G} *(1+\mathrm{v})(9)$

Similarly, when calculating the attraction of city $\mathrm{b}$ to city a, the relative gravity constant $\mathrm{K}$ can be adopted as follows:

Sba $=$ voj - oi average (10)

$\mathrm{Sba}=-\mathrm{v} * \mathrm{e}(11)$

$\mathrm{K}=\mathrm{G} *(1-\mathrm{v})(12)$

According to the above derivation, the gravitational orientation of the city will affect the vector direction of Sab, thus making the relative gravitational constant $\mathrm{K}$ different. The direction of the vector are relatively constant gravity is greater than the negative direction of relative gravity vector constants, the gravity model to calculate the directional gravity values, and in different vector in the direction of gravity values are not the same.

Integrated equation (2)-(4), the improved gravity model is:

$\mathrm{Fab}=\mathrm{G}(\mathrm{e}$

$+\mathrm{Sab}=0$ nwa-mna-mna-mna-mna-m $* \mathrm{n}=0$ na-nna $-\mathrm{m} *$ pb-nqb $-\mathrm{m}$ sigma $\mathrm{t}=0$ n(ba-tcab-ttab-t)(13)

\section{Inter-city gravity calculation}

The calculation of gravity between cities, first need to calculate the competitiveness of each city, through the index system, selection of normalization standardization method (mei-chuan lee, 2004) was carried out on the original data standardization, to adopt the method of mean square deviation decision-making after the standardization of data on the weight allocation (ming-tao wang, 1999). The results are shown in table 1 . 
Table 1 urban competitiveness of Wuhan "8+1" urban circle in 2012.

\begin{tabular}{|c|c|c|c|c|c|c|c|c|c|}
\hline $\begin{array}{c}\text { City } \\
\text { name }\end{array}$ & $\begin{array}{c}\text { Wu } \\
\text { han }\end{array}$ & $\begin{array}{c}\text { Xiao } \\
\text { gan }\end{array}$ & $\begin{array}{c}\text { Huang } \\
\text { gang }\end{array}$ & $\begin{array}{c}\text { Huang } \\
\text { shi }\end{array}$ & $\begin{array}{c}\text { Xian } \\
\text { ning }\end{array}$ & $\begin{array}{c}\mathrm{E} \\
\text { zhou }\end{array}$ & $\begin{array}{c}\text { Xian } \\
\text { tao }\end{array}$ & $\begin{array}{c}\text { Qian } \\
\text { jiang }\end{array}$ & $\begin{array}{c}\text { Tian } \\
\text { men }\end{array}$ \\
\hline $\begin{array}{c}\text { Urban } \\
\text { competitiveness }\end{array}$ & 61.011 & 8.021 & 7.331 & 6.948 & 5.313 & 3.991 & 2.622 & 2.466 & 2.297 \\
\hline
\end{tabular}

Note: selected from "study on the gravity pattern of Wuhan urban circle based on improved urban circle gravity model -- money spring lei"

Due to the direct of Wuhan city circle of railway transport is not perfect, for there is no direct railway services into and out of the two cities need to consider other cities as a transit point, we choose the shortest route to calculate the cost of transportation distance. Through equation (2), calculate the distance between cities (table 2).

Table 2 the transportation cost distance between the "8+1" urban circle in Wuhan in 2012.

\begin{tabular}{|c|c|c|c|c|c|c|c|c|c|}
\hline Distance & $\begin{array}{c}\text { Wu } \\
\text { han }\end{array}$ & $\begin{array}{c}\text { Xiao } \\
\text { gan }\end{array}$ & $\begin{array}{c}\text { Huang } \\
\text { gang }\end{array}$ & $\begin{array}{c}\text { Huang } \\
\text { shi }\end{array}$ & $\begin{array}{c}\text { Xian } \\
\text { ning }\end{array}$ & $\begin{array}{c}\text { E } \\
\text { zhou }\end{array}$ & $\begin{array}{c}\text { Xian } \\
\text { tao }\end{array}$ & $\begin{array}{c}\text { Qian } \\
\text { jiang }\end{array}$ & $\begin{array}{c}\text { Tian } \\
\text { men }\end{array}$ \\
\hline $\begin{array}{c}\text { Wu } \\
\text { han }\end{array}$ & -- & 32.27 & 62.16 & 30.79 & 24.90 & 26.30 & 53.19 & 77.15 & 91.89 \\
\hline $\begin{array}{c}\text { Xiao } \\
\text { gan }\end{array}$ & 32.27 & -- & 112.15 & 112.91 & 170.16 & 48.82 & 96.14 & 117.03 & 87.62 \\
\hline $\begin{array}{c}\text { Huang } \\
\text { gang }\end{array}$ & 62.16 & 112.15 & -- & 10.90 & 138.09 & 9.00 & 233.97 & 280.12 & 295.67 \\
\hline $\begin{array}{c}\text { Huang } \\
\text { shi }\end{array}$ & 30.79 & 112.91 & 10.90 & -- & 61.94 & 5.02 & 143.55 & 205.06 & 227.17 \\
\hline $\begin{array}{c}\text { Xian } \\
\text { ning }\end{array}$ & 24.90 & 170.16 & 138.09 & 61.94 & -- & 53.65 & 106.42 & 130.63 & 130.63 \\
\hline $\begin{array}{c}\text { E } \\
\text { zhou }\end{array}$ & 26.30 & 48.82 & 9.00 & 5.02 & 53.65 & -- & 137.07 & 196.24 & 217.02 \\
\hline $\begin{array}{c}\text { Qian } \\
\text { jiang }\end{array}$ & 53.19 & 96.14 & 233.97 & 143.55 & 106.42 & 137.07 & -- & 5.35 & 8.25 \\
\hline $\begin{array}{c}\text { Xian } \\
\text { tao }\end{array}$ & 77.15 & 117.03 & 280.12 & 205.06 & 130.63 & 196.24 & 5.35 & -- & 11.33 \\
\hline $\begin{array}{c}\text { Tian } \\
\text { men }\end{array}$ & 91.89 & 87.62 & 295.67 & 227.17 & 130.63 & 217.02 & 8.25 & 11.33 & -- \\
\hline
\end{tabular}

Note: selected from "study on the gravity pattern of Wuhan urban circle based on improved urban circle gravity model -- money spring lei"

Calculate the attraction between cities according to formula (13) and table 2-3. The obtained gravity matrix Fij is shown in table 3 . (Fij represents the attraction of city I to city $\mathrm{j}$ ) 
Table 3 the attraction between the " $8+1 "$ city circle in Wuhan in 2012.

\begin{tabular}{|c|c|c|c|c|c|c|c|c|c|}
\hline $\begin{array}{c}\text { Gravity } \\
\text { matrix Fij }\end{array}$ & $\begin{array}{l}\text { Wuh } \\
\text { an j }\end{array}$ & $\begin{array}{l}\text { Xiao } \\
\text { gan j }\end{array}$ & $\begin{array}{l}\text { Huang } \\
\text { gang j }\end{array}$ & $\begin{array}{c}\text { Huang } \\
\text { shi j }\end{array}$ & $\begin{array}{c}\text { Xian } \\
\text { ning j }\end{array}$ & $\begin{array}{c}\text { E } \\
\text { zhou j } \\
\end{array}$ & $\begin{array}{c}\text { Xiant } \\
\text { ao j }\end{array}$ & $\begin{array}{l}\text { Qian } \\
\text { jiang j }\end{array}$ & $\begin{array}{c}\text { Tian } \\
\text { men } \mathrm{j}\end{array}$ \\
\hline Wuhan $i$ & -- & $\begin{array}{c}27.2 \\
1\end{array}$ & $\begin{array}{c}13.0 \\
1\end{array}$ & $\begin{array}{c}25.0 \\
1\end{array}$ & $\begin{array}{c}24.1 \\
2\end{array}$ & $\begin{array}{c}17.4 \\
5\end{array}$ & 5.78 & 3.76 & 2.94 \\
\hline Xiaogan $i$ & 3.11 & -- & 0.79 & 0.74 & 0.38 & 1.02 & 0.36 & 0.28 & 0.35 \\
\hline $\begin{array}{l}\text { Huang } \\
\text { gang } i\end{array}$ & 1.38 & 0.26 & -- & 7.01 & 0.43 & 5.02 & 0.13 & 0.10 & 0.09 \\
\hline $\begin{array}{l}\text { Huang } \\
\text { Shi } i\end{array}$ & 2.53 & 0.25 & 2.33 & -- & 0.90 & 8.49 & 0.20 & 0.13 & 0.11 \\
\hline $\begin{array}{l}\text { Xian } \\
\text { Ning } i\end{array}$ & 1.92 & 0.12 & 0.14 & 0.29 & -- & 0.60 & 0.20 & 0.16 & 0.15 \\
\hline $\begin{array}{c}\text { E } \\
\text { Zhoui }\end{array}$ & 1.07 & 0.29 & 1.50 & 2.56 & 0.19 & -- & 0.12 & 0.08 & 0.06 \\
\hline $\begin{array}{l}\text { Xian } \\
\text { Tao i }\end{array}$ & 0.24 & 0.08 & 0.03 & 0.05 & 0.06 & 0.04 & -- & 1.81 & 1.10 \\
\hline $\begin{array}{c}\text { Qian } \\
\text { Jiangi }\end{array}$ & 0.15 & 0.06 & 0.02 & 0.03 & 0.04 & 0.02 & 0.60 & -- & 0.75 \\
\hline $\begin{array}{l}\text { Tian } \\
\text { Men } i\end{array}$ & 0.11 & 0.07 & 0.02 & 0.03 & 0.04 & 0.02 & 0.47 & 0.25 & -- \\
\hline
\end{tabular}

Note: selected from "study on the gravity pattern of Wuhan urban circle based on improved urban circle gravity model -- money spring lei"

\section{Pattern analysis}

According to the calculated gravity data, Wuhan's attraction to other cities is 8 to 30 times that of other cities. Wuhan's position in the city circle cannot be underestimated. As the leading city of the city, Wuhan has the function of driving the development of other cities. The spatial distribution of gravity value indicates that the economic relation between local cities in urban circle is large, but the whole is weak and the economic relation is unbalanced.

\section{Countermeasures to improve the gravity effect of Wuhan city circle}

\section{Optimize the industrial structure of Wuhan city circle}

In Wuhan city circle, some city functions are more closely related, but the connection strength between most cities is low. On the functional structure, the scale of urban scale in Wuhan city circle is unbalanced, and the industrial structure is not reasonable. Only by optimizing the industrial structure of the city circle can the Wuhan city circle be in a dominant position in the future development.

\section{Continue to strengthen Wuhan's core city status}

At present as a better development of the Yangtze river delta urban agglomeration and the core of the pearl river delta urban agglomeration economy level of development of Shanghai, Beijing and other parts of the city is much higher than in Wuhan, Wuhan urban circle want to have a better development, cannot be confined to the current size. Wuhan, as the core city of Wuhan city circle, should consolidate the existing core status and drive the development of surrounding cities, which will play a real strong radiation role.

\section{Strive to develop secondary core cities}

According to relevant statistics, the first degree of Wuhan city circle is as high as 7.68, equivalent to about three times the Yangtze River delta city cluster. On the one hand, Wuhan, as the first city in Wuhan city, has a strong economic development capacity. On the other hand, the development gap between cities in Wuhan city is large, and the development level of other cities is far behind that of Wuhan central city. Huangshi, the second largest city in Wuhan, has a distinct advantage in geographical location, with shangtong yu rong and lower toning Shanghai. It is dominated by heavy industry and rich in resources. Therefore, in the future the development of city circle, the can make use of the advantages of Yellowstone, increase the industry adjustment, to 
follow the pace of the first city, efforts to the development of competitive industries, so as to promote the overall development.

\section{Upgrade the industrial structure within the circle}

The urban economy of Wuhan city circle is at the early stage of industrialization, in addition to the high proportion of the third industry in Wuhan, almost all of the other 8 cities in three industries in the second industry is heavy, like electrical and mechanical, textile, food, building materials mainly. The third industry in the urban circle is not developed, especially the low level of service, such as finance and information, which leads to the unclear function of each city. Due to the influence of traditional planned economy, lack of information exchange and frequent economic intercourse, the duplication of construction is serious.

So, in order to better development of Wuhan city circle, from city to city to play to regional advantages, reasonable use of optimizing the resources distribution of circles, cultivating regional leading industries, the development of industrial cluster, mutual cooperation, complementary advantages and disadvantages.

\section{Accelerate the construction of Wuhan city circle financial system \\ Optimize the banking system and develop the money market system \\ 1mprove the banking system}

We will encourage state-owned commercial Banks to open Windows in surrounding cities, accelerate the pace of banking regional headquarters like Wuhan, and strengthen the degree of financial concentration in Wuhan. To break the pattern of the old institution setting and work on the integrated system of Wuhan city circle banking system, further strengthen the extension and radiation of the institutions in surrounding cities.

\section{Stablish an establish financial competition system}

We will deepen reform of the state-owned commercial banking system, improve its service and construction capacity in Wuhan's urban circle, and increase the vitality of state-owned commercial Banks. To encourage the diversity and standardization of forms of ownership among banking institutions and improve the service mechanism and capacity of the banking system. We will accelerate the reform and development of rural credit cooperatives in the inner circle, making it the main source of financing for farmers.

\section{Promote banking integration}

First, it is common in the city circle to carry out the same city clearing, raise capital efficiency. The second is to speed up regional paper center in Wuhan market and the integration of large settlement system construction, increase the paper market trading tools and trading varieties, expand business pilot scale, development paper specializes in institutions, all the cities within the circle domain specialized paper market main body.

\section{Promote innovation in financial instruments}

Actively explore the development of entrusted loans and other financial instruments, and promote the innovation of financial instruments. By means of the reloan instrument, we can support the development of small and medium-sized financial institutions in the circle and speed up the inter-bank transaction of urban Banks in the circle.

We will actively build Wuhan financial street and guide financial institutions to the financial center.

To study and effectively learn from domestic and foreign experience, accelerate the reform of the financial system and innovation of financial instruments, and create a financial center environment. We will support and promote Wuhan to plan and build financial intensive areas, and form a relatively complete regional headquarters of financial institutions, "financial street". We will actively introduce foreign investment and provide more opportunities for Wuhan's financial construction.

\section{Strengthen market legal system construction}

We will establish a system of laws and regulations conducive to the administration and construction of the administrative region, standardize the integration process of Wuhan urban circle as soon as possible, and build a perfect platform for the rule of law. On the basis of abolishing the 
contradictory local policies, the regional common legislation should be strengthened to regulate the integration process of Wuhan urban circle.

Lengthen cooperation in industry and commerce administration

To strengthen the administration of industry and commerce, we should break down the trade barriers, pay attention to the major problems in administrative management, realize the unification of business administration, rectify and standardize market order.

\section{Will improve the level of opening to the outside world}

\section{Improvement of Wuhan external open center}

We will provide perfect service for Wuhan city circle and accelerate the construction of Wuhan bonded logistics center. In view of these two points, we can energetically develop the exhibition economy, strengthen regional foreign trade center, cultural exchange center, logistics transportation hub and external finance, information and other service system construction. To increase the opportunity of foreign consulates to improve customs clearance and entry and exit efficiency.

\section{Promote and expand investment attraction}

We will continue to increase the utilization rate of foreign capital, and expand investment attraction as an opportunity for the development of the city circle. We will work hard to build more capital intensive areas and vigorously promote investment promotion. We will improve the construction of the investment project bank of Wuhan city circle, and realize the unified foreign investment attraction of the city circle. We will encourage the diversity of foreign investment, and absorb multinational enterprises to set up regional headquarters and research and development bases in Wuhan city circle. We will properly guide foreign investment, use foreign capital to accelerate the pace of tertiary industry, and actively guide foreign investment in key industrial parks with potential.

\section{Accelerate the steady and coordinated development of foreign trade}

We will carry out joint and reorganization of assets, optimize the export structure, promote the transformation and upgrading of processing trade, and promote the formation of a group of export-oriented enterprises with strong international competitiveness. According to the characteristics of the industrial structure of the city circle, the international market objectives of different industries are determined, and targeted marketing strategies are proposed to expand the market share. Accelerate the pace of key export construction. Construction of IT product export base, honey export base and automobile and parts export base, etc., to form the agglomeration effect. Implement the strategy of winning quality and expand the international market with brand effect. We will increase our love for imports and control and regulate the import of important resources, and maintain a good order in the import business.

\section{Conclusion}

In this paper, gravity model is introduced to reflect the relative rule of city. This paper puts forward some countermeasures to the problems existing in Wuhan city circle. However, there are many factors influencing the gravity index of the model, and the research needs to be improved.

\section{Acknowledgement}

Management science and engineering key discipline of Hubei province 2017 open fund project ZDXK2017KF10

\section{Reference}

[1] liu jisheng, Chen yanguang. 2000. General form and application method of fractal urban gravity model [J]. Geoscience, 20(6): 528-533. 
[2] Chen yanguang, liu jisheng. 2002. Urban spatial correlation and power spectrum analysis based on gravity model: theoretical proof of gravity model, function promotion and application example [J]. Geographical research, 21(6): 742-752.

[3] li meijuan, Chen guohong, Chen yetai. 2004. Research on the standardization of indicators in comprehensive evaluation [J]. China management science, 10(12): 45-48.

[4] wang mingtao. 1999. The decision method of deviation and mean square deviation of weight determination in multi-index comprehensive evaluation [J]. Chinese soft science, 8(8): 100-101, 107. 